PREPARED FOR THE U.S. DEPARTMENT OF ENERGY, UNDER CONTRACT DE-AC02-76CH03073

PPPL-3989

PPPL-3989

UC-70

\title{
Development of NSTX \\ Particle Control Techniques
}

by

H.W. Kugel, R. Maingi, M. Bell, D. Gates, K. Hill, B. LeBlanc,

D. Mueller, R. Kaita, S. Paul, S. Sabbagh, C.H. Skinner,

V. Soukhanovskii, B. Stratton, and R. Raman

July 2004

NM|

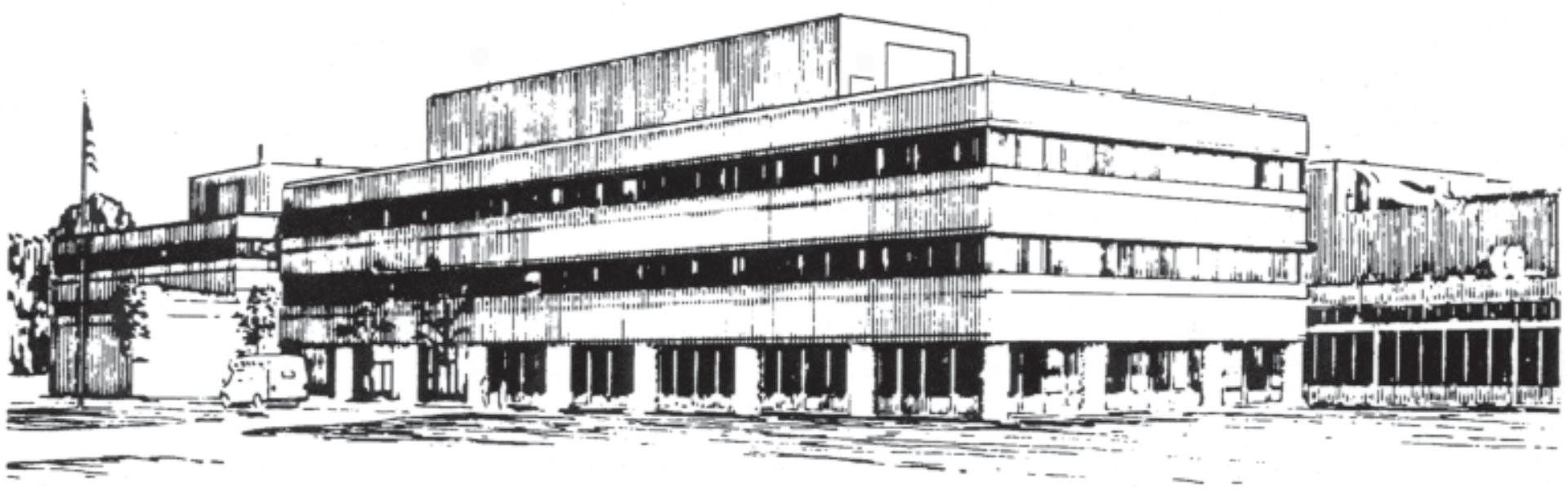

PRINCETON PLASMA PHYSICS LABORATORY PRINCETON UNIVERSITY, PRINCETON, NEW JERSEY 


\section{PPPL Reports Disclaimer}

This report was prepared as an account of work sponsored by an agency of the United States Government. Neither the United States Government nor any agency thereof, nor any of their employees, makes any warranty, express or implied, or assumes any legal liability or responsibility for the accuracy, completeness, or usefulness of any information, apparatus, product, or process disclosed, or represents that its use would not infringe privately owned rights. Reference herein to any specific commercial product, process, or service by trade name, trademark, manufacturer, or otherwise, does not necessarily constitute or imply its endorsement, recommendation, or favoring by the United States Government or any agency thereof. The views and opinions of authors expressed herein do not necessarily state or reflect those of the United States Government or any agency thereof.

\section{Availability}

This report is posted on the U.S. Department of Energy's Princeton Plasma Physics Laboratory Publications and Reports web site in Fiscal Year 2004. The home page for PPPL Reports and Publications is: http://www.pppl.gov/pub_report/

DOE and DOE Contractors can obtain copies of this report from:

U.S. Department of Energy

Office of Scientific and Technical Information

DOE Technical Information Services (DTIS)

P.O. Box 62

Oak Ridge, TN 37831

Telephone: (865) 576-8401

Fax: (865) 576-5728

Email: reports@adonis.osti.gov

This report is available to the general public from:

National Technical Information Service

U.S. Department of Commerce

5285 Port Royal Road

Springfield, VA 22161

Telephone: $1-800-553-6847$ or

(703) $605-6000$

Fax: (703) 321-8547

Internet: http://www.ntis.gov/ordering.htm 


\title{
Development of NSTX particle control techniques
}

\author{
H. W. Kugel ${ }^{\text {a }}$, R. Maingi ${ }^{\text {b }}$, M. Bell ${ }^{\text {a }}$, D. Gates ${ }^{\text {a }}$, K. Hill ${ }^{\text {a }}$, B. LeBlanc ${ }^{\text {a }}$, \\ D. Mueller a , R. Kaita ${ }^{\text {a }}$, S. Paul a , S. Sabbagh ${ }^{\text {c }}$, C. H. Skinner ${ }^{\text {a }}$, \\ V. Soukhanovskii ${ }^{\mathrm{d}}$, B. Stratton ${ }^{\mathrm{a}}$, R. Raman ${ }^{\mathrm{e}}$ \\ ${ }^{a}$ Princeton Plasma Physics Laboratory, Princeton, NJ 08543, USA \\ ${ }^{b}$ Oak Ridge National Laboratory, Oak Ridge, TN 37831, USA \\ ${ }^{c}$ Columbia University, New York, NY 10027, USA \\ ${ }^{d}$ Lawrence Livermore National Laboratory, Livermore, CA 94551, USA \\ ${ }^{e}$ University of Washington, Seattle, WA 98195, USA
}

\begin{abstract}
NSTX High Harmonic Fast Wave (HHFW) current drive discharges will require density control for acceptable efficiency. In NSTX, this involves primarily controlling impurity influxes and recycling. We have compared boronization on hot and cold surfaces, varying helium glow discharge conditioning (HeGDC) durations, helium discharge cleaning, brief daily boronization, and between discharge boronization to reduce and control spontaneous density rises. Access to Ohmic H-modes was enabled by boronization on hot surfaces, however, the duration of the effectiveness of hot and cold boronization was comparable. A 15 min HeGDC between discharges was needed for reproducible L-H transitions. He discharge conditioning yielded slower density rises than $15 \mathrm{~min}$ of HeGDC. Brief daily boronization followed by a comparable duration of applied HeGDC restored and enhanced good conditions. Additional brief boronizations between discharges did not improve plasma performance (reduced recycling, reduced impurity luminosities, earlier L-H transitions, longer plasma current flattops, higher stored energies) if conditions were already good. Between discharge boronization required increases in the NSTX duty cycle due to the need for additional HeGDC to remove codeposited D.
\end{abstract}




\section{Introduction}

The investigation of non-inductive current drive with the goal of eliminating the central solenoid from future machines is a major focus of international Spherical Torus research and the National Spherical Torus Experiment (NSTX) program [1]. Elements of the NSTX current drive research program include High Harmonic Fast Wave (HHFW) current drive ( 100 kA achieved) and Coaxial Helicity Injection (CHI) (400 kA achieved). Integrated scenario modeling of NSTX HHFW current drive discharges [2] shows that an average plasma density less than $\mathrm{n}_{\mathrm{e}} \sim 3 \times 10^{19} \mathrm{~m}^{-3}$ is optimal for acceptable HHFW current drive efficiency. However, during long-pulse NBI-heated H-modes, the density rises continuously, reaching up to $\mathrm{n}_{\mathrm{e}} \sim 7 \times 10^{19} \mathrm{~m}^{-3}$ in $0.3 \mathrm{~s}$. Analysis of the time dependence of these density rises [3] has found $\tau_{\mathrm{p}}{ }^{*} \sim 0.5 \mathrm{~s}$ or $\sim 10 \mathrm{x} \tau_{\mathrm{E}}$. It has become evident that the existing NSTX particle control techniques $[4,5]$ of gas puffing, high temperature PFC bakeout, boronization on room temperature substrates, and brief HeGDC wall conditioning between discharges need augmenting to provide plasma density control for longer pulse operation.

We report on a comparison of boronization on hot and cold substrates, brief daily boronization, between discharge boronization, extended HeGDC between discharges, and He discharge conditioning to reduce and control spontaneous density rises, and in particular control $\tau_{\mathrm{p}}^{*}$ for improved HHFW current drive efficiency, as well as, for transport studies, and power and particle handling research.

\section{Comparison of boronization on hot and cold surfaces}

The NTSX plasma facing surface is about $41 \mathrm{~m}^{2}$, consisting of graphite tiles on power handling surfaces (75.6\%), and the 304-SS midplane vessel wall (24.4\%). During bakeout following a vent, the graphite is baked to $300-350^{\circ} \mathrm{C}$ and the vessel walls to $150^{\circ} \mathrm{C}$. 25 boronizations have been performed on the room temperature plasma facing surfaces using 10 $\mathrm{g}$ of deuterated trimethyl boron $\left(\mathrm{B}\left(\mathrm{CD}_{3}\right)_{3}\right)$ injected into a HeGDC [6]. A typical boronization is applied in about $140 \mathrm{~min}$, and is followed by $2 \mathrm{hrs}$ of HeGDC to remove the codeposited deuterium from the deposition layer. Based on machine performance and spectroscopic signals indicative of relatively higher impurity luminosities, these boronizations have been performed in NSTX most typically about every 200-400 discharges or about every 2-3 weeks for $I_{p}$ pulse lengths of less than $1 \mathrm{sec}$ and duty cycles of 10-20 min between discharges. 
However, boronization has been applied even more frequently, if necessary, to restore wall conditions when severely degraded following particular experiments. Although such room temperature boronization has been effective in enabling high performance in NSTX to date $[4,5]$, a test of boronization on high temperature substrates was made. The goal of testing the effectiveness of hot boronization on graphite surfaces $\left(300-350^{\circ} \mathrm{C}\right)$ and the vessel wall $\left(150^{\circ} \mathrm{C}\right)$ was to determine if changes in codeposition, deposited film microstructure, and uniformity could reduce impurity traps and, hence change recycling. A hot boronization was performed after pump-down, following a brief venting of the vessel. The hot and cold (room temperature) boronizations were compared using D lower single null (LSN), $600 \mathrm{kA}$ plasma current $\left(\mathrm{I}_{\mathrm{p}}\right)$, Ohmic, and LSN, $\mathrm{I}_{\mathrm{p}} 800 \mathrm{kA}$, NBI fiducial discharges.

Following hot boronization, a significant improvement in the performance of the initial Ohmic and NBI fiducial discharges was observed relative to those following cold boronization. The Ohmic fiducial discharges exhibited the most favorable Ohmic performance to date. The previously elusive Ohmic H-mode was achieved after the 2nd discharge, and maintained in many discharges thereafter. This relatively facile transitioning to the Ohmic H-mode may be related to the lower $\mathrm{D}_{\alpha}$ luminosity observed after hot boronization, which may in turn be due to less retention of codeposited $D_{2}$ during boronization on hot surfaces, and possible reduced porosity and trapping sites in depositions on higher temperature surfaces. Laboratory work has indicated that boron films grown at high temperatures exhibit characteristics that imply a different microstructure $[7,8]$. The D LSN NBI fiducial discharges exhibited the most promising first-day-NBI operation to date following a vent. However, although the first NBI fiducial discharges transitioned easily to $\mathrm{H}$-modes, these discharges exhibited a $\mathrm{D}_{\alpha}$ luminosity comparable to NBI discharges following cold boronization. This may have been due to the $\mathrm{D}_{2}$ wall loading resulting from the 56 Ohmic discharges that preceded the D LSN NBI fiducial discharges. However, while the initial performance of NBI fiducials following hot boronization was significantly improved relative to cold boronization, as the fluence to the wall increased with succeeding NBI discharges, the operating conditions following hot boronization deteriorated (increased recycling, increased impurity luminosities, later L-H transitions, shorter $\mathrm{I}_{\mathrm{p}}$ flattops, lower stored energies), and became indistinguishable from those following cold boronization, These results may indicate that as the fluence to the wall increases, erosion and similar changes to 
the deposition microstructure eventually dominated over the initial deposition conditions. Figure 1 shows the behavior of the core luminosity ratios for LSN NB fiducial discharges after hot (B-23) and cold (B-24, B-25) boronization. The wider discharge number interval following B-24 included many cycles of the discharge timing clock for field-only tests and for data acquisition tests without plasma. The differences in impurity behavior following each boronization (Fig.1) resulted from the differences in power deposition and plasma configurations used for the various experiments. Following B-23 and B-25, for example, wall conditions deteriorated more rapidly following high power, long pulse experimentation as compared to more unchanging configurations used for the $\mathrm{H}$-mode threshold studies following B-24.

\section{Comparison of applying HeGDC between discharges and helium discharge conditioning}

The duration of between discharge HeGDC was varied from 7 to 15 min to investigate ways to optimize conditions for density control, boundary physics characterization experiments, and sensitive studies of early $\mathrm{H}$-mode access as a method for limiting rapid penetration of the current density during ramp up to achieve access to $q_{\min }>>1$. In summary, it was found that at least a 15 min HeGDC between discharges was needed for reproducible timing of the L-H transition. Shorter HeGDC applications were found to delay the L-H transition, and could eventually result in a higher L-H power threshold by mid or latter part of run day. Figure 2 shows how the time of the L-H transition moves earlier in the discharge as the duration of the applied HeGDC was increased.

Figure 3 shows a comparison of the density rise for D, LSN, NBI discharges after the application 15 min of HeGDC between discharges and a technique which applied a 5 min HeGDC followed by a double null diverted (DND), He, I 500 kA, Ohmic conditioning discharge. Both D discharges transitioned to H-mode, but the $\mathrm{D}$ discharge preceded by the $\mathrm{He}$ conditioning discharge exhibited a lower density rise which caused a locked mode (rare in NSTX H-modes). This lower density rise in NSTX is attributed to the more effective removal of absorbed deuterium in the walls, and the subsequent reduction in recycling, due to the intense and energetic wall conditioning of the He conditioning discharge as compared to that of the only applying HeGDC as was also found on TFTR [9]. We intend to investigate if this 
result is due to the GDC geometry. This provides a prescription for slowing the rise in density during ramp up and improving density control for NSTX experiments sensitively dependent on wall recycling conditions.

\section{Comparison of applying daily boronization and boronization between discharges}

Experiments were performed to investigate ways that might stabilize conditions between standard full boronizations, and when conditions are good to determine if they could be improved. These experiments focused on the following questions: "Is a brief daily boronization (e.g., in the morning, prior to daily operation) sufficient? If brief daily boronization is good, is between discharge boronization even better? Does more frequent, briefer boronization improve reproducibility?".

Brief daily boronization and between discharge boronization were tested about midway between 2 standard full boronizations. A standard full boronization on NSTX consumes $10 \mathrm{~g}$ of deuterated trimethylboron in about $140 \mathrm{~min}$, followed by $2 \mathrm{hrs}$ of HeGDC to remove codeposited deuterium. In order to determine the optimal balance between the duration of a brief boronization, the required HeGDC for desorbing the codeposited deuterium, and the subsequent fiducial performance, 5 brief boronizations were performed, ranging in duration from $1 \mathrm{~min}\left(7.2 \times 10^{-2} \mathrm{~g}\right)$ to $17 \mathrm{~min}(1.2 \mathrm{~g})$ followed by HeGDC applications ranging from 5 to $30 \mathrm{~min}$. Figure 4 shows the relative luminosities following a $17 \mathrm{~min}$ boronization followed by a $17 \mathrm{~min}$ HeGDC and a $15 \mathrm{~min}$ boronization followed by a 30 min HeGDC using high performance LSN NBI fiducials. The $17 \mathrm{~min}$ HeGDC following the 17 min boronization was in about the same proportion as the $2 \mathrm{hr}$ HeGDC following the standard full boronization applied in about $140 \mathrm{~min}$. The longer HeGDC was applied after the 15 min boronization to test for the effect of additional removal of codeposited D. It was found that the luminosity ratios for $\mathrm{Da} / \mathrm{BII}$ measured at $0.250 \mathrm{sec}$ exhibited the largest fraction change. The BII/CIII luminosity ratio was relatively constant. This may be due to the signals having measured both the fresh and the residual passivated products ( $\mathrm{B}$ and $\mathrm{C}$ ) from previous standard boronizations, and hence, sampled approximately the same deposition stoichiometry. Figure 5 shows the experimental sequence used for comparing the effect of various brief boronizations, different durations of HeGDC, and He conditioning discharges using D DND NB fiducials. In NSTX, preceding the D discharges with He discharge 
conditioning was more effective than HeGDC alone in restoring good conditions. The resultant conditions were later used to produce D LSN discharges with the highest stored energies for 4.5 MW NBI discharges to date $\left(\sim 300 \mathrm{~kJ}, \tau_{\mathrm{E}} \sim 45-50 \mathrm{msec}\right)$.

\section{Discussion}

It was found that boronization on hot surfaces yields a significant improvement in initial operating conditions (lower recycling, lower impurity luminosities, earlier L-H transitions, longer $I_{p}$ flattops, higher stored energies) relative to boronization on cold surfaces, but that the duration of the improved operating conditions following hot and cold boronization was comparable as fluence to the wall increased with succeeding discharges. A 15 min HeGDC between discharges was needed for reproducible L-H transition timing. In NSTX, preceding the D discharges with He discharge conditioning was more effective than HeGDC alone in restoring good conditions. This result is consistent with previous work on TFTR [9], although on other machines, HeGDC between discharges has been found to be sufficient. We intend to investigate if this is due to the NSTX GDC geometry. Brief daily boronization followed by a comparable duration of applied HeGDC restored and enhanced good operating conditions. Additional brief boronization between discharges with relatively good operating conditions produced no improvement. Between discharge boronization increases the normal NSTX 10-20 min duty cycle (for $I_{p}$ discharges less than $1 \mathrm{sec}$ ) due to the need to apply HeGDC for a sufficient duration to remove codeposited D. Remaining questions involve using between discharge sample analysis to measure changes in microstructure as fluence increases, determining the most sensitive fiducial discharges, and the optimal figures of merit for determining the frequency of applying brief daily boronization. In addition, more work is needed to determine the optimal balance between the frequency of applying boronization, the amount of boronization (duration), and the duration of the succeeding HeGDC for reproducible operating conditions and accessing high performance regimes. 


\section{Acknowledgment}

This work is supported by U.S. Department of Energy Contracts, DE-AC0276CH03073, DE-AC05-00OR22725, DE-FG02-99ER54523 and DE-FG03-99ER54361, W7405-ENG-36,. We wish to acknowledge the technical contributions of W. Blanchard, J. Winston, T. Czeizinger J. Desandro, J. Gething, J. Kukon and the NSTX Engineering and National Research Teams. 


\section{References}

[1] E. Synakowski, et al., Nuc. Fusion, 43 (2003) 1653.

[2] C. Kessel, Proceedings of the NSTX 5-Year Plan Review, June 2003, Princeton, NJ.

[3] R. Maingi, et al., Plasma Physics of Controlled Fusion, 45 (2003) 657.

[4] C. H. Skinner, et al., Nucl. Fusion 42 (2002) 329.

[5] H.W. Kugel, et al., J. Nucl. Mater. 313-316 (2003) 187.

[6] W. Blanchard, et al., Proceedings of the IEEE/NPSS Symposium on Fusion Engineering in Atlantic City, NJ, January 21-25, 2002.

[7] S. Veprek, et al., J. Nucl. Mater. 162-164 (1989) 724.

[8] J. Winter in "Physical Processes of the Interaction of Fusion Plasmas with Solids", Academic Press, 1996, p 217.

[9] J. D. Strachan, et al., J. Nucl. Mater. 196-198 (1992) 28. 


\section{Figure Captions}

Fig. 1 Core luminosity ratios for LSN NB fiducial discharges after hot (B-23) and cold (B24, B-25) boronization. The wider interval following B-24 included many cycles of the discharge clock for field-only tests and data acquisition tests without plasma. The differences in impurity behavior following each boronization resulted from the differences in power deposition and plasma configurations used for these experiments.

Fig. 2 The change in time (sec) of the L-H transition from the L-H transition in the preceding discharge. The $\mathrm{L}-\mathrm{H}$ transition moves earlier in the discharge as the duration of the applied HeGDC is increased.

Fig. 3 Comparison of the density rise for D, LSN, NBI discharges after the application 15 minutes of HeGDC between discharges and a technique which applied a 5 minute HeGDC followed by a He, DND $I_{p} 500 \mathrm{kA}$, Ohmic conditioning discharge. Both D discharges transitioned to $\mathrm{H}$-mode, but the $\mathrm{D}$ discharge preceded by the $\mathrm{He}$ conditioning discharge exhibited a lower density rise which caused a locked mode (rare in NSTX H-modes).

Fig. 4 Relative change in luminosity ratios following brief boronizations followed by a comparable duration of HeGDC to remove codeposited D.

Fig. 5 Conditioning sequence for comparing the effect of various brief boronizations, different durations of HeGDC and He conditioning discharges using D DND NB fiducials. 


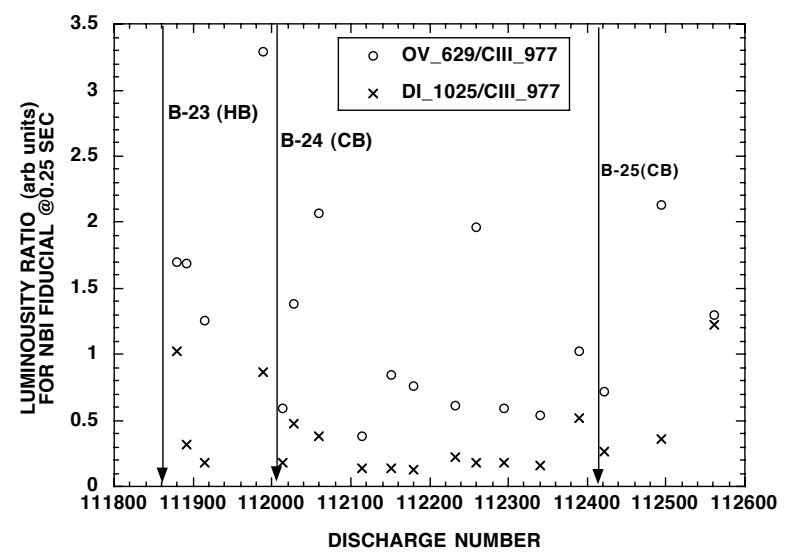

Fig. 1 Core luminosity ratios for LSN NB fiducial discharges after hot (B-23) and cold (B-24, B-25) boronization. The wider interval following B-24 included many cycles of the discharge clock for field-only tests and data acquisition tests without plasma. The differences in impurity behavior following each boronization resulted from the differences in power deposition and plasma configurations used for these experiments 


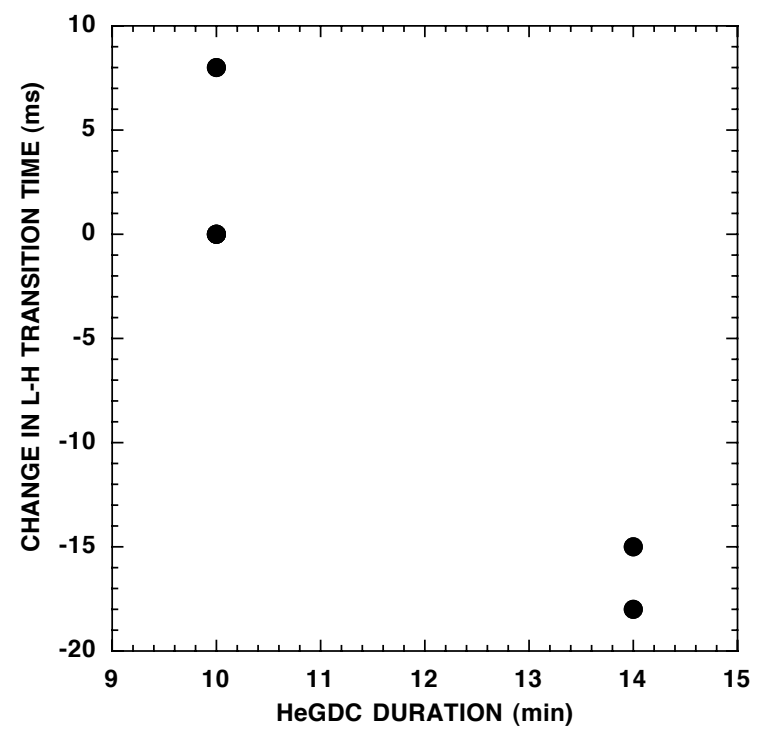

Fig. 2 The change in time (sec) of the L-H transition from the L-H transition in the preceding discharge. The L-H transition moves earlier in the discharge as the duration of the applied HeGDC is increased. 


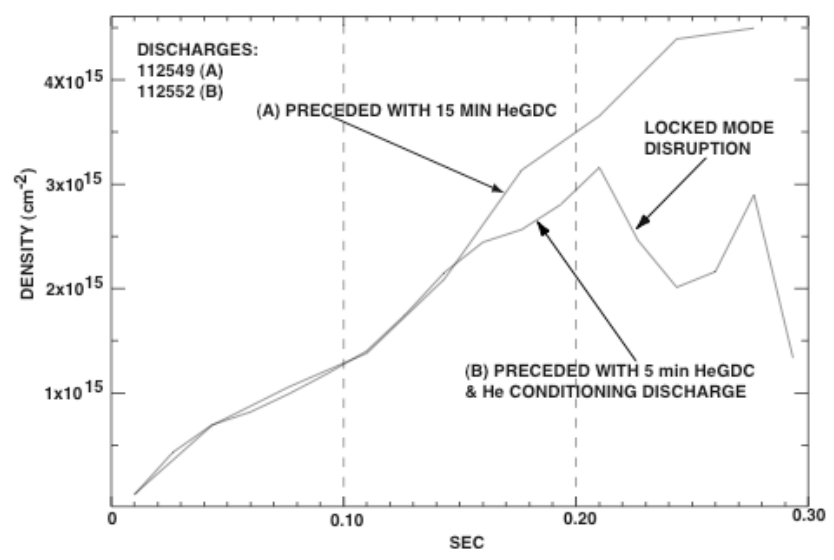

Fig. 3 Comparison of the density rise for D, LSN, NBI discharges after the application 15 minutes of HeGDC between discharges and a technique which applied a 5 minute HeGDC followed by a He, DND, $\mathrm{I}_{\mathrm{p}} 500 \mathrm{kA}$, Ohmic conditioning discharge. Both D discharges transitioned to $\mathrm{H}$-mode, but the $\mathrm{D}$ discharge preceded by the $\mathrm{He}$ conditioning discharge exhibited a lower density rise which caused a locked mode (rare in NSTX H-modes). 


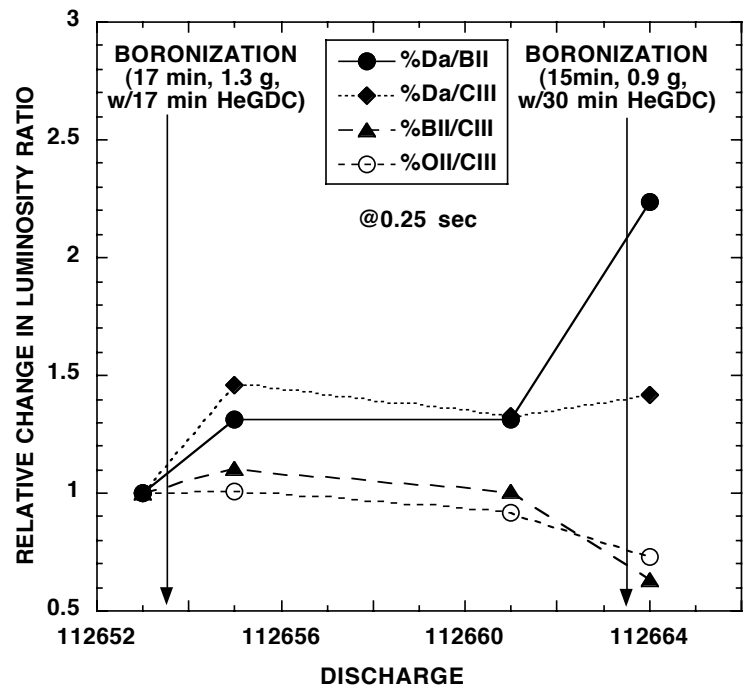

Fig. 4 Relative change in luminosity ratios following brief boronizations followed by a comparable duration of HeGDC to remove codeposited D. 


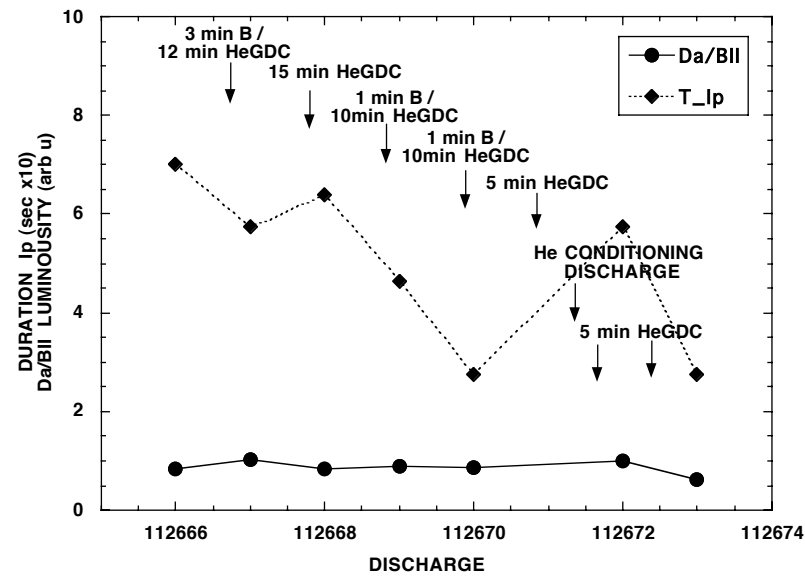

Fig. 5 Conditioning sequence for comparing the effect of various brief boronizations, different durations of HeGDC and He conditioning discharges using D DND NB fiducials. 


\section{External Distribution}

Plasma Research Laboratory, Australian National University, Australia

Professor I.R. Jones, Flinders University, Australia

Professor João Canalle, Instituto de Fisica DEQ/IF - UERJ, Brazil

Mr. Gerson O. Ludwig, Instituto Nacional de Pesquisas, Brazil

Dr. P.H. Sakanaka, Instituto Fisica, Brazil

The Librarian, Culham Laboratory, England

Mrs. S.A. Hutchinson, JET Library, England

Professor M.N. Bussac, Ecole Polytechnique, France

Librarian, Max-Planck-Institut für Plasmaphysik, Germany

Jolan Moldvai, Reports Library, Hungarian Academy of Sciences, Central Research Institute for Physics, Hungary

Dr. P. Kaw, Institute for Plasma Research, India

Ms. P.J. Pathak, Librarian, Institute for Plasma Research, India

Ms. Clelia De Palo, Associazione EURATOM-ENEA, Italy

Dr. G. Grosso, Instituto di Fisica del Plasma, Italy

Librarian, Naka Fusion Research Establishment, JAERI, Japan

Library, Laboratory for Complex Energy Processes, Institute for Advanced Study, Kyoto University, Japan

Research Information Center, National Institute for Fusion Science, Japan

Dr. O. Mitarai, Kyushu Tokai University, Japan

Dr. Jiangang Li, Institute of Plasma Physics, Chinese Academy of Sciences, People's Republic of China

Professor Yuping Huo, School of Physical Science and Technology, People's Republic of China

Library, Academia Sinica, Institute of Plasma Physics, People's Republic of China

Librarian, Institute of Physics, Chinese Academy of Sciences, People's Republic of China

Dr. S. Mirnov, TRINITI, Troitsk, Russian Federation, Russia

Dr. V.S. Strelkov, Kurchatov Institute, Russian Federation, Russia

Professor Peter Lukac, Katedra Fyziky Plazmy MFF UK, Mlynska dolina F-2, Komenskeho Univerzita, SK-842 15 Bratislava, Slovakia

Dr. G.S. Lee, Korea Basic Science Institute, South Korea

Institute for Plasma Research, University of Maryland, USA

Librarian, Fusion Energy Division, Oak Ridge National Laboratory, USA

Librarian, Institute of Fusion Studies, University of Texas, USA

Librarian, Magnetic Fusion Program, Lawrence Livermore National Laboratory, USA

Library, General Atomics, USA

Plasma Physics Group, Fusion Energy Research Program, University of California at San Diego, USA

Plasma Physics Library, Columbia University, USA

Alkesh Punjabi, Center for Fusion Research and Training, Hampton University, USA

Dr. W.M. Stacey, Fusion Research Center, Georgia Institute of Technology, USA

Dr. John Willis, U.S. Department of Energy, Office of Fusion Energy Sciences, USA

Mr. Paul H. Wright, Indianapolis, Indiana, USA 
The Princeton Plasma Physics Laboratory is operated by Princeton University under contract with the U.S. Department of Energy.

\author{
Information Services \\ Princeton Plasma Physics Laboratory \\ P.O. Box 451 \\ Princeton, NJ 08543
}

Phone: 609-243-2750

Fax: 609-243-2751

e-mail: pppl_info@pppl.gov

Internet Address: http://www.pppl.gov 